\title{
Ontogeny of feeding performance and biomechanics in coyotes
}

\author{
S. La Croix ${ }^{1}$, M. L. Zelditch ${ }^{2}$, J. A. Shivik ${ }^{3}$, B. L. Lundrigan ${ }^{4}$ \& K. E. Holekamp ${ }^{1}$ \\ 1 Department of Zoology, Michigan State University, East Lansing, MI, USA \\ 2 Museum of Paleontology, University of Michigan, Ann Arbor, MI, USA \\ 3 USDA Wildlife Services National Wildlife Research Center and Utah State University, Logan, UT, USA \\ 4 Michigan State University Museum and Department of Zoology, Michigan State University, East Lansing, MI, USA
}

\begin{abstract}
Keywords
ontogeny; feeding performance; bite strength; dentition; skull morphology; carnivore; geometric morphometrics; life history.
\end{abstract}

\section{Correspondence}

Suzanne La Croix, Department of Zoology, 203 Natural Science Building, Michigan State University, East Lansing, MI 48824, USA. Tel: + 15174491965

Email: lacroixs@msu.edu

Received 31 March 2011; revised 21 June 2011; accepted 4 July 2011

doi:10.1111/j.1469-7998.2011.00847.x

\begin{abstract}
Developing organisms must reconcile conflicts between demands of survival within the current life-history stage, with those of maturation, while negotiating the transitions through succeeding stages. In the case of feeding performance, the parts of the feeding apparatus and their biomechanics must maintain functional integrity to meet the feeding needs of a juvenile even as they develop toward their adult form. We concurrently examine the ontogenetic relationships of feeding performance, dentition and feeding biomechanics, relative to key life-history events, utilizing samples drawn from the same population of known-age coyotes Canis latrans. The development of feeding performance is asynchronous with development of both feeding biomechanics and skull morphology; feeding performance lags during ontogeny despite surprisingly large early mechanical advantage of the temporalis, due in part, to early relative maturity of mandibular shape. Feeding performance and biomechanics, like skull morphology, mature well after weaning at 6 weeks of age. Late maturation of bite strength and feeding performance is mediated by ongoing and continued growth of the temporalis muscles as measured by maximum zygomatic arch breadth (ZAB). Males and females may resolve developmental conflicts differently, as females trade earlier maturity for smaller maximum ZAB, decreased relative bite strength and diminished feeding performance, compared with males. The asynchrony of feeding performance development seen in coyotes, is also characteristic of a highly specialized carnivore, the spotted hyena, but coyotes have a much less protracted development, being handicapped relative to adults for a much shorter time. This developmental asynchrony between feeding performance and morphology suggests that a certain minimum threshold of physical growth and development, together with the associated development of biomechanics, are required to produce effective mastication. The relationships among biomechanics, life-history schedules and ontogeny of feeding performance have obvious implications for fitness.
\end{abstract}

\section{Introduction}

Mammalian life-history stages are useful constructs for examining periods of mostly continuous development which occur between discrete life-history milestones. During ontogeny, each life-history stage represents a temporal ecological niche to which animals must be adapted in order to survive to the next stage. Developing organisms are continually changing their morphologies and demands of survival within the current lifehistory stage may conflict with those of maturation due to differing demands on limited physiological, morphological and behavioral resources. Understanding how developing animals resolve these time critical challenges of growth and survival as they transition through succeeding life-history stages can illuminate the relationship between form and function.
Behavior and morphology are subject to developmental constraints that may yield a form that is sub-optimal for solving the problems confronted by the organism. During early postnatal development, the young mammal's feeding apparatus undergoes tremendous changes in both size and shape, and the cranium and mandible must function to satisfy the feeding needs of a juvenile, even as it develops toward an adult form (La Croix et al., 2011) (Fig. 1). In some species, ontogenetic changes in the skull yield juveniles and subadults with bite strength ability that is considerably less than that of adults (Binder \& Van Valkenburgh, 2000; Erickson, Lappin \& Vliet, 2003; Christiansen \& Adolfsen, 2005). Even though young mammals enjoy a brief period of nutritional dependence on the parents, at weaning, juveniles must be capable of processing adult foods or adopt a 


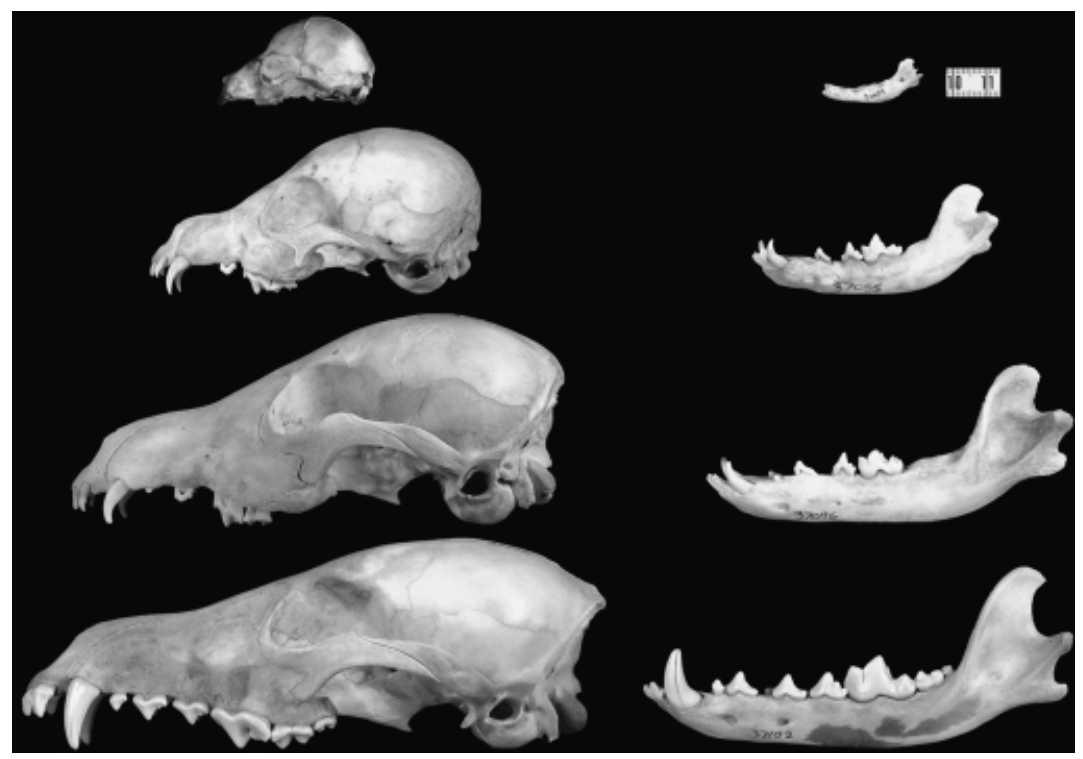

Figure 1 Ontogenetic variation in cranial and mandibular size and shape among coyotes Canis latrans aged, from top, 1 day, 6 weeks, 12 weeks and 26 weeks is visually dramatic.

different diet (Wainwright \& Reilly, 1994; Monteiro, Lessa \& Abe, 1999; Herrel \& Gibb, 2006). Carnivores, especially, face tremendous challenges during ontogeny as they attempt to provision themselves and compete with adults despite their immature morphology. Small changes in morphology can have profound effects on an animal's functional capabilities (Koehl, 1996). The period of deciduous tooth eruption and replacement presents a challenge to early food processing that is unique to young mammals. It has been suggested that the mechanical nature of deciduous teeth (e.g. greater brittleness and sharpness) may somewhat offset the mechanical disadvantage that juveniles encounter with their smaller muscle mass (Binder \& Van Valkenburgh, 2000). Even so, these teeth, which are sized to fit into the much smaller pre-weaning feeding apparatus, undergo replacement because they no longer meet the functional demands imposed by the succeeding life-history stage.

Recent work on the spotted hyena (Tanner et al., 2010) showed that juveniles and subadults in this durophagous species remain handicapped for an extended period of time after weaning due to protracted development of a robust feeding apparatus capable of cracking open large bones. It remains unclear to what extent, and for how long, the developing feeding apparatus handicaps juveniles in other, less specialized, carnivore species. In contrast to spotted hyenas, coyotes show no specialized adaptations for durophagy and they consume relatively little bone in their diet (Andelt et al., 1987; Arjo, Pletscher \& Ream, 2002). With the behavioral plasticity to consume small and large prey, live in pairs or packs and colonize rural and urban environments, the coyote's diet and lifestyle are opportunistic and generalist (Bekoff, 1977; Bekoff \& Gese, 2003). Their generalized carnivore morphology makes them appropriate for comparisons with more highly specialized carnivores, such as hyenas.

To investigate the extent to which coyotes might be handicapped as juveniles, we took advantage of a unique opportunity to assess the ontogeny of feeding performance in known-age coyotes, and examine feeding biomechanics with an ontogenetic series of known-age coyote skulls. The samples were drawn from the same population although different individuals were utilized in the analyses of feeding performance and of biomechanics. Here, we describe the ontogeny and maturation of feeding performance, tooth eruption and replacement schedules, and estimates of feeding biomechanics in coyotes. We fit non-linear growth models to our data to describe development of feeding performance and biomechanics over the course of ontogeny, examine sexual dimorphism and assess development within the context of the coyote's life history. We then describe the ontogenetic patterns and temporal coincidence of feeding performance and biomechanics including their synchrony, or lack thereof, and implications for functionality of the feeding apparatus. Finally, we contrast these patterns of development in coyotes with those in spotted hyenas, to uncover more generalized patterns of development and examine their relationship to life-history events. Understanding relationships among biomechanics, life-history schedules, and ontogeny of feeding performance is important because these relationships have obvious implications for fitness.

\section{Methods}

\section{Subjects and specimens}

Feeding performance trials were conducted with known-age coyotes from a captive colony comprised of animals of wildcaught and colony parentage, maintained at the USDA/ APHIS Wildlife Services National Wildlife Research Center's Logan Field Station in Millville, UT between 2004 and 2006. A total of 44 pups (26 males, 18 females) from 11 litters participated in the trials; three of the litters (20 animals) were wild-born in 2004, while eight of the litters 
(24 animals) were captive-born in 2005 (supporting information Table S1). All animals were captive reared, and although the current study did not investigate whether the observed ontogenetic patterns are equivalent to those found in the wild, rearing conditions at the Logan Field Station were designed to be naturalistic. All animals were maintained on a commercially produced wet food diet designed for fur bearing animals which contained chicken (beaks, feet and feathers) and grain. Before weaning, pups also received a milk replacement powder commercially produced for puppies and reconstituted with water; during weaning, pups received a pea-sized kibble version of the wet food diet, moistened with water. Pups younger than 6 weeks were maintained in litter groups. Following weaning at c. 6 weeks, pups were housed in either small groups of littermates (two or three individuals) or singly, until 4 months, when all animals were subsequently housed singly. Captiveborn pups were initially housed indoors in $0.6 \times 1.2 \mathrm{~m}$ wire dog kennels with plastic floor pans while wild-born pups were maintained in a wire enclosure in an open pole-barn with gravel flooring. Following weaning, animals were moved to $3.7 \times 1.2 \mathrm{~m}$ chain-link fenced enclosures with a concrete floor and containing a $0.6 \mathrm{~m}^{2}$ round plastic den box within the pole barn. Animals had no access to bones, other foods or chew toys except during performance trials.

Feeding biomechanics were investigated using an ontogenetic series of 187 coyote skulls (102 males and 85 females) of known age (La Croix et al., 2011), collected incidentally from captive animals of wild-caught and colony parentage that were maintained at the Logan Field Station between 1979 and 2006. Individuals ranged in age from 1 day to 13.3 years, including 79 specimens under the age of 6 months. All skulls were catalogued into either the Michigan State University Museum collection, or the Logan Field Station collection in Millville, UT (supporting information Table S2). Within the ontogenetic series, 179 specimens were captive-born, including all specimens under the age of 1 year, while eight were wild-born. Exact dates of death were known for all individuals and exact dates of birth were known for all captive-born animals. For animals obtained from the wild as pups, dates of birth were estimated by the original collectors based on deciduous tooth eruption and den observations, and those dates of birth were used here. Collector and animal records for all specimens are maintained at the Logan Field Station. USDA/APHIS/WS/ NWRC IACUC approved the study protocol QA-1179.

\section{Feeding performance}

Feeding performance trials were conducted from 2004 to 2006 using repeated measures on 44 coyotes between the ages of 6 and 80.3 weeks. Pups born in 2004 were tested at 14 -week intervals; the testing interval was later adjusted and pups born in 2005 were tested every 8 weeks, in order to document performance at as many ages as possible. Feeding performance trials were carried out in home enclosures $18-24 \mathrm{~h}$ after the animals' last feedings. Variation in feeding performance (mechanical processing ability) was deter- mined using a standardized food item, a commercially produced dog biscuit (following Tanner et al., 2010) which challenged the animals to break and crush a hard object into pieces that could be swallowed. This task is not unlike a wild coyotes' need to crush the skeletons and skulls of large rodents and lagomorphs and the exoskeletons of insects before swallowing. On the day of testing, animals that did not consume a pre-test biscuit (a $4 \mathrm{~g}$, Iams brand puppy dog biscuit) within 5 min of delivery, with the Tester (S. L. C.) present in the kennel block, were excluded from the test. Qualifying animals were then presented with a standardized food item, a $32 \mathrm{~g}$, Iams brand, adult large dog biscuit. Three trials were conducted serially, with at least a $60 \mathrm{~s}$ delay between finishing ingestion of one biscuit and delivery of the next; animals that failed to consume a biscuit within 10 min were excluded from further testing for that day. Each trial was videotaped in natural light using a Sony Handycam Vision CCD-TRV65 NTSC - VideoHi8TR Steady Shot with $\times 72$ digital zoom (Sony Corporation, Tokyo, Japan). The video camera was mounted on a tripod outside the subject's kennel with a viewpoint $0.92 \mathrm{~m}$ above the ground. The time (in seconds) required to consume the biscuit was later calculated from these videotapes. Our measure of feeding performance was consumption time, defined as the sum of the periods of continuous and sustained chewing, including breaking up of the biscuit into pieces that could be swallowed. Timing began with the first audible crunch of the biscuit into more than one piece and concluded when the biscuit was completely consumed. Only the best consumption time from each animal's three consecutive biscuit trials was used in feeding performance analyses, provided that best time was for a biscuit completely processed within the 10 -min trial period; two females, aged 20 weeks, and one female, aged 28 weeks, were excluded from the analysis as they failed to completely consume a biscuit within $600 \mathrm{~s}$. All 6-week old pups, none of which were able to bite biscuits ( $4 \mathrm{~g}$ or $32 \mathrm{~g}$ ) into pieces, were assigned the maximum consumption time of $600 \mathrm{~s}$ in order to permit the development of growth curves of feeding performance and the calculation of conservative estimates of maturation.

\section{Direct measurements of bite strength}

We obtained 40 direct measurements of bite strength using a bite force transducer (Kistler, Amherst, NY) from 12 animals, ranging in age from 52 to 406 weeks, at Logan Field Station (see supporting information S3). The transducer was baited with meat and hand-held by the investigator (S. L. C.). Direct measurement of bite strength required an animal's willingness to approach the investigator at the kennel fence and voluntarily bite down on the transducer. When a coyote voluntarily bit down, a piezoelectric plate embedded in the transducer measured the force generated in Newtons, and this was recorded from a handheld charge amplifier. Similar devices have been used with wild hyenas (Tanner, 2007), captive hyenas (Binder, 1998; Binder \& Van Valkenburgh, 2000), captive short-tailed opossums (Thompson, Biknevicius \& German, 2003) and with both 
captive and wild American alligators (Erickson et al., 2003). While voluntary bites probably do not reflect maximum bite force since feedback from the periodontal ligaments protects an animal from biting so forcefully that it damages its teeth, the voluntary bites do provide functional measurements of bite force for comparison with mechanical estimates of bite strength. We report the best voluntary bite force generated for each individual and the tooth position of the bite force transducer; three individuals provided data at both 52 and 104 weeks of age and one individual provided data at both 406 and 414 weeks of age.

\section{Tooth eruption and replacement}

As is characteristic of most mammals, coyotes are diphyodont, having two sets of teeth during their lifetime. During ontogeny, feeding performance may be affected by the loss of these deciduous teeth and the eruption of adult teeth. Here, the ontogenetic series of known-age skulls was visually examined for tooth eruption and replacement patterns. A tooth was recorded as erupted if any part of that tooth (e.g. a dorsal tip) protruded above the alveolus. Previously, it had been observed (by S. L. C.) during the flensing and preparation of these skull specimens that a tooth which protruded above the alveolus also pierced the gum line. Therefore, we also included data for the tooth eruption of the 24 coyote pups used in the feeding performance trials between the ages of 4 and 12 weeks; again, a tooth that protruded above the gum line was recorded as an erupted tooth. To document patterns of tooth eruption and replacement, we recorded the age at which all specimens or live animals evidenced eruption of the deciduous or adult tooth of interest.

\section{Mechanical advantage and bite strength}

Mammalian mastication, including that of carnivores, has been described by various authors (Turnbull, 1970; Simpson, 1978; Hiiemae \& Crompton, 1985; Schumacher, 1985; Van Valkenburgh, 1989; Weijs, 1994; Langenbach, 2001). Carnivore jaw movement is restricted to a mostly hinge-like action in a single plane and has been modeled as a modified Class I lever (Turnbull, 1970). By modeling the jaw as a lever, it becomes possible to assess feeding ability and to calculate the mechanical advantage of the feeding apparatus (Radinsky, 1981; Greaves, 1983; Greaves, 1985; Thomason, 1991; Smith, 1993). In addition, relative bite strength can be inferred by estimating both the mechanical advantage of the primary masticatory muscles (here, the temporalis) and the size of those muscles (Radinsky, 1981; Hildebrand, 1984; Binder, 1998). These simple lever models are most useful for deriving a comparative bite strength measure, rather than absolute values; for some skull shapes, these models underestimate relative bite strength (Ellis et al., 2008).

The length of the in-lever arm is measured as the distance between the muscle insertion point and the mandibular condyle, and the length of the out-lever arm is measured as the distance between the mandibular condyle and the bite
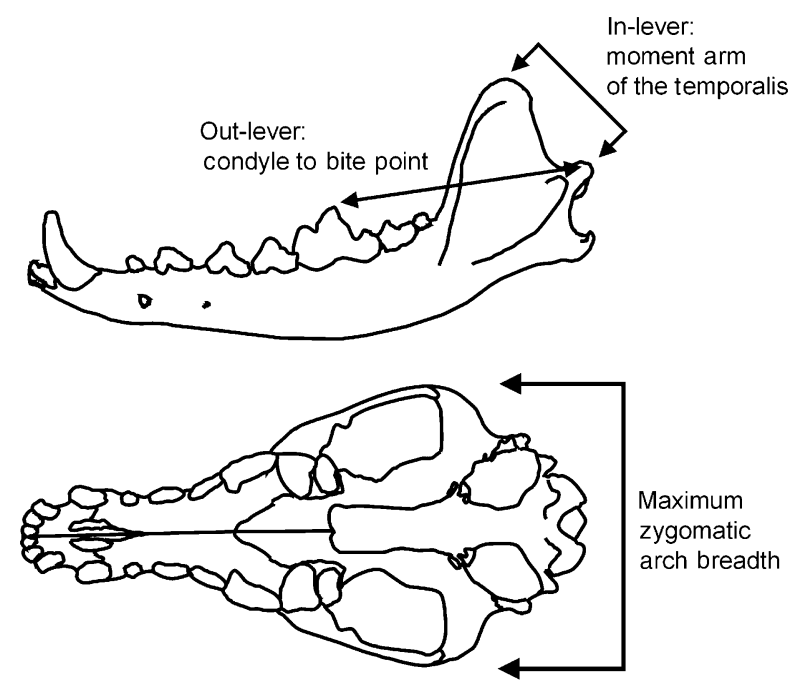

Figure 2 Traditional linear measures of the skull used to calculate mechanical advantage of the temporalis, and to estimate bite strength. The in-lever arm length is the distance between the mandibular condyle and the dorsal tip of the coronoid process. The out-lever arm length is the distance between the mandibular condyle and the bite point (here, the dorsal tip of the mandibular carnassial tooth, M1). Maximum zygomatic arch breadth was a proxy for muscle mass in estimating bite strength.

point on the mandible (Fig. 2). Adductor muscle size is estimated from the maximal width across the zygomatic arches (Radinsky, 1981; Gittleman \& Van Valkenburgh, 1997; Binder, 1998). Over ontogeny, as the length of the inlever arm increases relative to that of the out-lever arm, mechanical advantage increases (Hurov et al., 1988; Gittleman \& Van Valkenburgh, 1997). Here, the length of the in-lever arm for the primary masticatory muscle, the temporalis, was measured as the distance between the dorsal tip of the coronoid process and the mandibular condyle, and the length of the out-lever arm was measured as the distance between the mandibular condyle and the bite point (Fig. 2). The bite point was the highest cusp of the mandibular first molar; this carnassial tooth is the largest tooth in the mouth.

Linear measures of the skull were obtained using a digital caliper accurate to $0.01 \mathrm{~mm}$; each measurement was taken in triplicate and then averaged. Following Radinsky (1981), mechanical advantage was calculated as the in-lever arm length divided by the out-lever arm length. Evaluation of relationships among the measurements comprising mechanical advantage was accomplished by regression of the out-lever on the in-lever and by examination of the residuals; statistical analyses were performed using STATISTICA, version 8.0 (StatSoft Inc., 2007, http://www. statsoft.com). Relative bite strength was calculated by multiplying mechanical advantage of the temporalis by maximum zygomatic arch breadth (ZAB) (Fig. 2, the widest point on the skull) (Radinsky, 1981; Hildebrand, 1984; Binder, 1998). 


\section{Age and timing of maturation}

To determine the age at which feeding performance and biomechanical variables (mechanical advantage, maximum $\mathrm{ZAB}$ and relative bite strength) attained adult values, we used a series of non-linear growth models to find the one that best fit the data. Coyotes are known to exhibit sexual size dimorphism as adults (Bekoff, 1977), so we considered male and female data separately when fitting growth curves. Eight models (Chapman-Richards, Logistic, Monomolecular, Gompertz, German Gompertz, Von Bertalanffy, Quadratic and Linear) were fitted to the data for each feeding performance and biomechanical variable and assessed for their relative goodness-of-fit using Akaike information criterion (AIC) (following Zelditch et al., 2003). The model with the lowest AIC value was judged to be the best so long as the residuals were not serially autocorrelated. Some models were excluded because they induced autocorrelations among residuals in one or more of the analyses; where several models fit equally well, the model with the highest AIC weight was selected as best (supporting information Table S4).

For feeding performance, we chose the Gompertz model as formalized by Fiorello \& German (1997), herein referred to as the German Gompertz model (following Zelditch et al., 2003), because this model fit the data well for both sexes and was the only model that did not induce autocorrelations among residuals for this variable (Table 1, supporting information Table S4). This model was the basis for estimating the parameters of feeding performance maturation:

$$
x(t)=A e^{-k e^{-b t}}
$$

where $x(t)$ is feeding performance at time $t, A$ is the asymptotic maturity, $k$ is the initial rate of growth (initial rate of approach to asymptotic value) and $b$ is the decay of the growth rate (Gaillard et al., 1997; Zelditch et al., 2003).

No growth model could be fit to the data for mechanical advantage of the temporalis for either sex due to autocorrelations among the residuals.

For maximum ZAB, we chose the monomolecular model (following Gaillard et al., 1997) because it not only fit the data well for both sexes, but also had the highest AIC weight of the several models that fit equally well (Table 1, supporting information Table S4). This model was the basis for estimating the parameters of maximum
ZAB maturation:

$$
x(t)=A\left\{1-e^{k\left(T_{0}-t\right)}\right\}
$$

where $x(t)$ is maximum ZAB at time $t, A$ is the asymptotic maturity, $k$ is the rate of growth (rate of approach to asymptotic value) and $T_{0}$ is the age at which growth begins (Gaillard et al., 1997; Zelditch et al., 2003).

For relative bite strength, we chose the logistic model (following Gaillard et al., 1997) because this model fit the data well for both sexes and it had a higher AIC weight than the general Chapman-Richards model (Table 1, supporting information Table S4). This model was the basis for estimating the parameters of relative bite strength maturation:

$$
x(t)=A /\left\{1+e^{k\left(T_{0}-t\right)}\right\}
$$

where $x(t)$ is the relative bite strength at time $t, A$ is the asymptotic maturity, $k$ is the rate of growth (rate of approach to asymptotic value), and $T_{0}$ is the age at the curve inflexion point (where growth has attained $50 \%$ of asymptotic value) (Gaillard et al., 1997; Zelditch et al., 2003).

For all variables, we report age at maturity as the estimated age at which the measurement of interest reaches $95 \%$ of asymptotic (adult) value (following Tanner et al., 2010). Data for individuals above the $95 \%$ breakpoint were subsequently regressed on age to ensure that age had no further significant impact on the measurement of interest. Evaluation of growth models and estimation of parameters were performed using GrowChoice (Sheets, 2003).

\section{Results}

\section{Feeding performance}

Six-week-old coyotes were unable to bite a $32 \mathrm{~g}$ biscuit into pieces (Fig. 3). After 12 weeks of age, however, animals successfully consumed the biscuit within $600 \mathrm{~s}$. As expected, coyote feeding performance improved over ontogeny, as evidenced by reduced biscuit consumption times (Fig. 3). Males showed faster processing times than females, at most ages (Fig. 3).

\section{Measured bite strength}

Although we recorded 40 bites on the bite force transducer

\begin{tabular}{|c|c|c|c|c|c|c|c|}
\hline & \multirow[b]{2}{*}{ Best-fit model } & \multicolumn{3}{|l|}{ Female } & \multicolumn{3}{|l|}{ Male } \\
\hline & & AIC weight & $\mathrm{AC}$ & $\%$ Var & AIC weight & $\mathrm{AC}$ & $\% \operatorname{Var}$ \\
\hline Feeding performance & German Gompertz & 1.000 & NS & 0.862 & 1.000 & NS & 0.918 \\
\hline \multicolumn{8}{|l|}{ Biomechanics } \\
\hline Maximum ZAB & Monomolecular & 0.4486 & NS & 0.992 & 0.4619 & NS & 0.991 \\
\hline Relative bite strength & Logistic & 0.7082 & NS & 0.978 & 0.7287 & NS & 0.976 \\
\hline
\end{tabular}
from 12 coyotes, for a number of reasons, we were unable to

Table 1 Best-fitting models for the estimates of feeding performance and skull biomechanics maturation

The AIC weight evaluates relative goodness-of-fit by balancing the distance between model and data by degrees of freedom. AC refers to serial autocorrelation among residuals of the model ('NS' indicates there was no statistically significant serial autocorrelation). Per cent variance explained (\% Var) by the best-fit model is also given. 

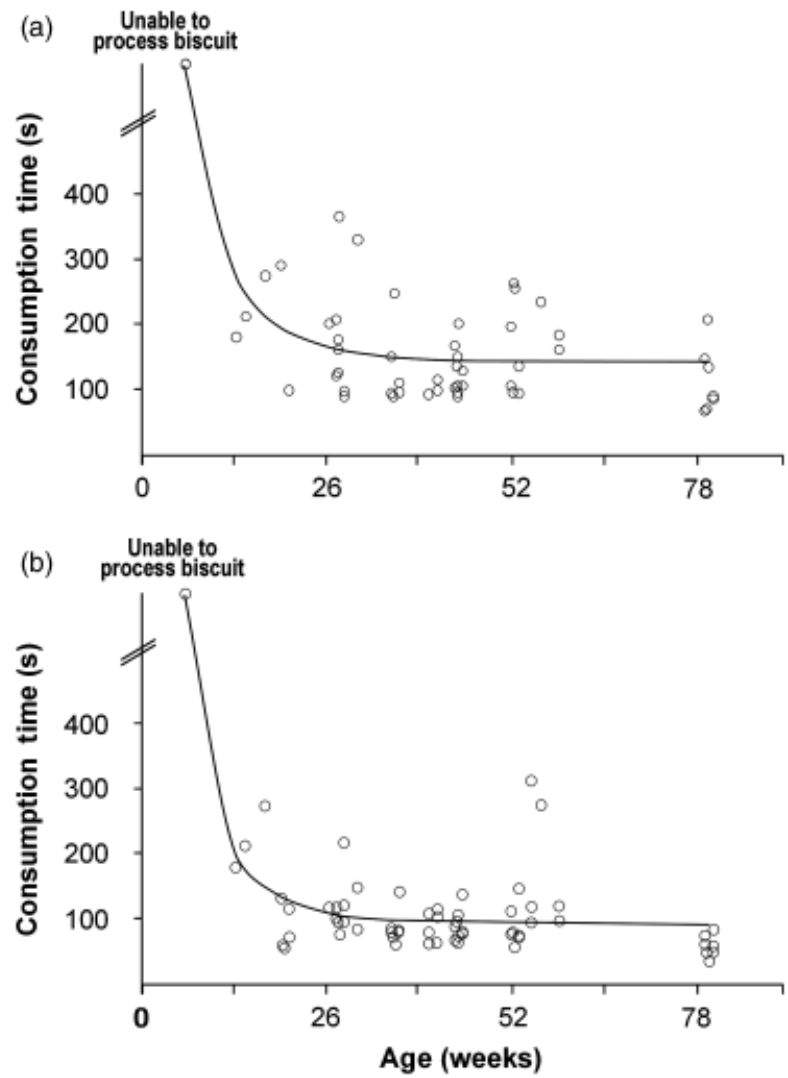

Figure 3 Growth plots of coyote feeding performance for females (a) and males (b) as measured by consumption time, in seconds, for a $32 \mathrm{~g}$ dog biscuit. At 6 weeks of age, coyote pups of both sexes were unable to process the biscuit. Only data performance for animals under 81 weeks of age are shown here.

collect sufficient data to document early ontogenetic changes in bite strength. First, some animals, especially juveniles, were simply unwilling to approach the transducer in proximity to the investigator. Second, animals willing to interact with the transducer would frequently remove the meat covering, test the transducer gently with their teeth and then cease interacting with the device. Further, some used their incisors while others used their carnassials. The individual that produced the largest bite force did so in repeated bouts of highly motivated tugging with the transducer positioned at his carnassial teeth. The bite force data we collected showed that older animals exhibited greater bite strength compared with younger animals, that males bit more forcefully than females of the same age, and that greater bite strength was generated at the carnassial (P4) position compared with those generated more anteriorly (Fig. 4). The largest bite force of $708 \mathrm{~N}$ was obtained from our oldest subject, a male aged 414 weeks.

\section{Tooth eruption and replacement}

An examination of the ontogenetic series of coyote skulls revealed that eruption of the deciduous teeth begins at

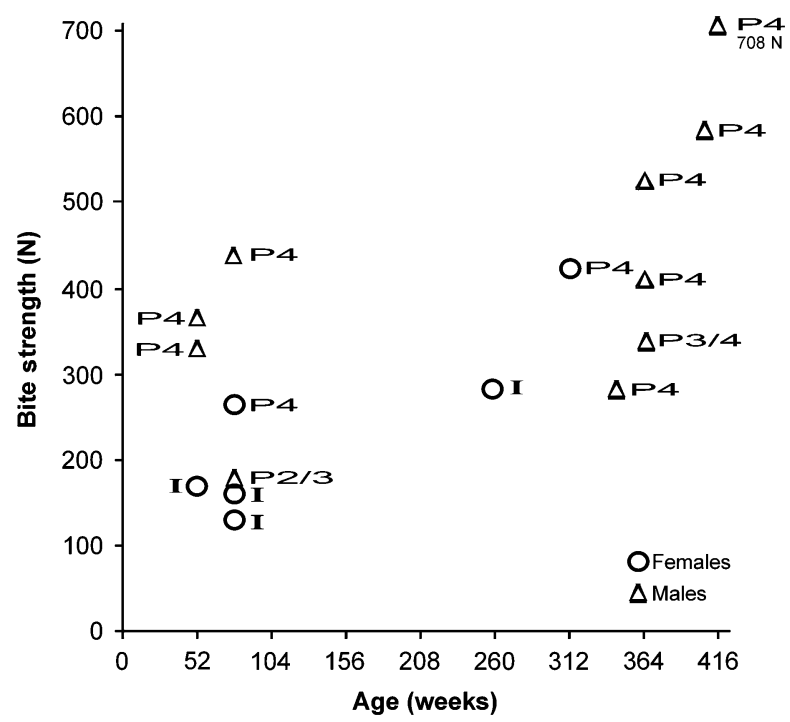

Figure 4 Plot of bite strength, measured in Newtons (N), obtained using a piezoelectric transducer, for male and female coyotes. The tooth position of the transducer during the bite is indicated: incisors (I); premolar 2/3 (P2/3); carnassial (P4).

c. 2 weeks of age. This concurs with existing literature on coyote tooth eruption: upper canines (Day 14), lower canines and upper incisors (Day 14-15), and lower incisors (Day 16) (Bekoff \& Jamieson, 1975; Bekoff, 2001). Further, we observed that by weaning at 6 weeks of age, the coyote pup dental formula is $\mathrm{I} 3 / 3 \mathrm{C} 1 / 1 \mathrm{P} 2 / 2 \mathrm{M} 1 / 1$ for 28 deciduous teeth total. The specific teeth present in the 6-week-old pup are $\mathrm{dI} 1, \mathrm{dI} 2, \mathrm{dI} 3, \mathrm{dC} 1, \mathrm{dP} 2, \mathrm{dP} 4$ and $\mathrm{dM} 1$ in the upper jaw and di1, di2, di3, dc1, dp2, dp4 and dm1 in the lower jaw (see supporting information Fig. S1). Note that $\mathrm{dP} 4 / \mathrm{dm} 1$ constitute the deciduous carnassial pair. The first permanent teeth, $\mathrm{P} 1 / \mathrm{p} 1$, erupt at 8 weeks of age and are fully erupted by 12 weeks of age. Replacement of the deciduous incisors begins by 12 weeks, with lower incisors lost first, followed by upper incisors; adult incisors are fully present by 18 weeks of age. Between 14 and 20 weeks, the remaining canines, premolars and molars are replaced, and adult teeth, $\mathrm{P} 3 / \mathrm{p} 3$ and M2/m2, erupt. By 21 weeks of age, coyotes lack only the adult $\mathrm{m} 3$ in the lower jaw; this tooth erupts during the 21 st week. By 26 weeks of age, coyotes have attained their complete adult dental formula of $\mathrm{I} 3 / 3, \mathrm{C} 1 / 1, \mathrm{P} 4 / 4, \mathrm{M} 2 /$ 3 for 42 teeth total.

\section{Mechanical advantage and bite strength}

The ontogeny of mechanical advantage of the temporalis did not follow a traditional growth pattern in coyotes, unlike feeding performance and other biomechanical estimates. Instead, mechanical advantage data formed two discrete clouds, one containing smaller values representing young animals, and the other containing larger values representing older animals (Fig. 5). The transition between these two clouds of data points occurred in the age range during which the deciduous carnassials and most of the 


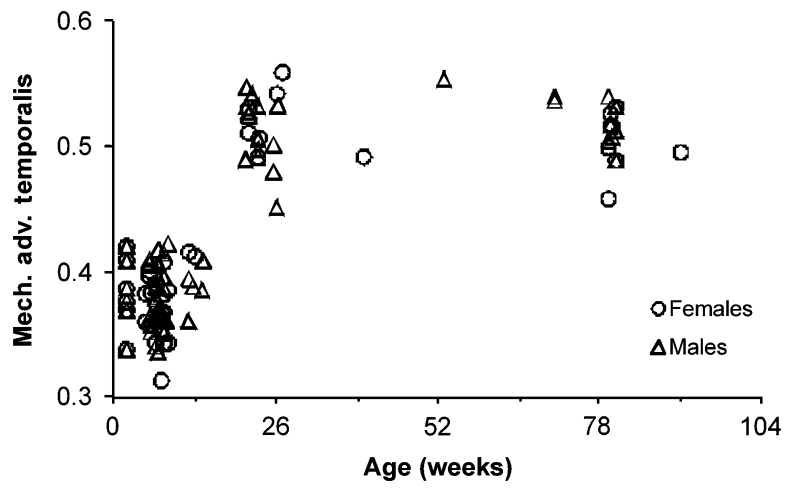

Figure 5 Plot of mechanical advantage of the temporalis for coyotes by age. Only data for coyotes aged $<100$ weeks are diagrammed.

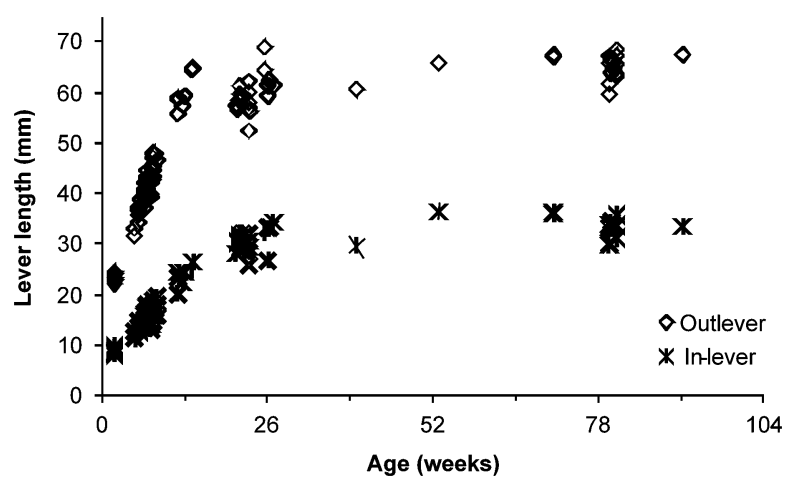

Figure 6 Growth plots for the components of the mechanical advantage of the temporalis: the in-lever arm length (distance between the mandibular condyle and the dorsal tip of the coronoid process) and out-lever arm length (distance between the mandibular condyle and the bite point). Only data for coyotes aged $<100$ weeks are diagrammed.

post-canine teeth were replaced. Indeed, the mechanical advantage in the younger group with deciduous dentition was significantly lower than in the older group of animals with adult dentition (supporting information Fig. S2). Mechanical advantage for coyote pups aged 2-14 weeks ranged from 0.313 to 0.420 , with some 2-week-old pups having a mechanical advantage equivalent to pups that were 10 weeks older. Mechanical advantage for coyotes over the age of 21 weeks ranged from 0.451 to 0.559 , with animals aged 21 weeks exhibiting a mechanical advantage equivalent to animals twice that age.

Examination of the components of mechanical advantage of the temporalis showed that the ontogenies for both the inlever arm length and the out-lever arm length were characterized by early rapid growth (Fig. 6). However, while outlever arm length increased more quickly than did in-lever arm length at the earliest ages (Fig. 6, supporting information Fig. S3), the latter continued to grow after the length of the out-lever arm stabilized (supporting information Fig. $\mathrm{S} 3$ ). It was also noted that the lever arm lengths for animals under 14 weeks of age represented animals with primarily deciduous dentition, whereas those for older animals repre-
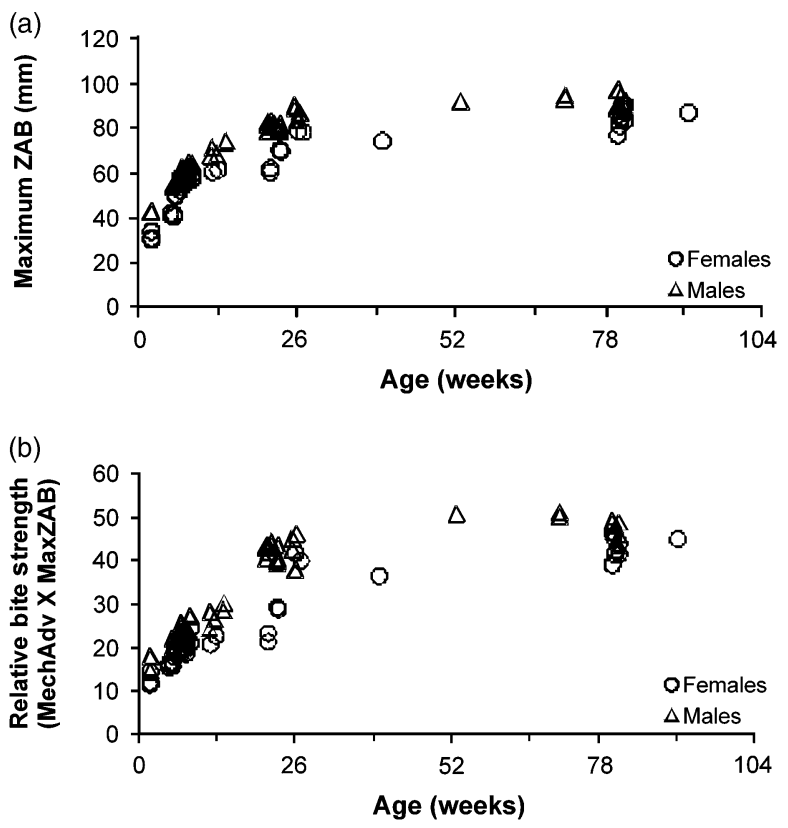

Figure 7 Plots of maximum zygomatic arch breadth (ZAB), as measured from skulls (a), and relative bite strength, as estimated by models (b), by age, in weeks, for coyotes. Only data for coyotes aged $<100$ weeks are diagrammed.

sented animals with adult dentition. Further, the bite point physically shifted during tooth replacement so that the endpoint of the out-lever arm length moved from the deciduous carnassial tooth to the newly erupted adult carnassial tooth. Before the replacement of the deciduous carnassial teeth, the out-lever arm underwent an unusually large increase in length at 12-14 weeks of age which, in a punctuated increase, brought its length within the range of animals over 6 weeks older.

Early growth in maximum ZAB (Fig. 7a) and relative bite strength (Fig. 7b) exhibited patterns similar to those for feeding performance and lever arm lengths: they underwent rapid early growth before asymptotic maturation was achieved by 30 (maximum ZAB) and 31.5 weeks (relative bite strength) of age. Maximum ZAB increased especially quickly at the youngest ages.

\section{Ages at maturity}

The German Gompertz growth model, the best-fitting model for feeding performance (Table 1, supporting information Table S4), indicated that adult feeding performance was not attained until 34.6 weeks in males and 36 weeks in females; asymptotic feeding performance was achieved significantly faster by males than females $(P=0.001)$ (Table 2$)$. The monomolecular growth model, the best-fitting model for maximum ZAB (Table 1, supporting information Table S4), is typified by extremely rapid growth at the youngest ages. Despite explosive early growth, maximum ZAB did not reach maturity until 26.9 weeks in females and 30.4 weeks in males; asymptotic maximum $\mathrm{ZAB}$ was 


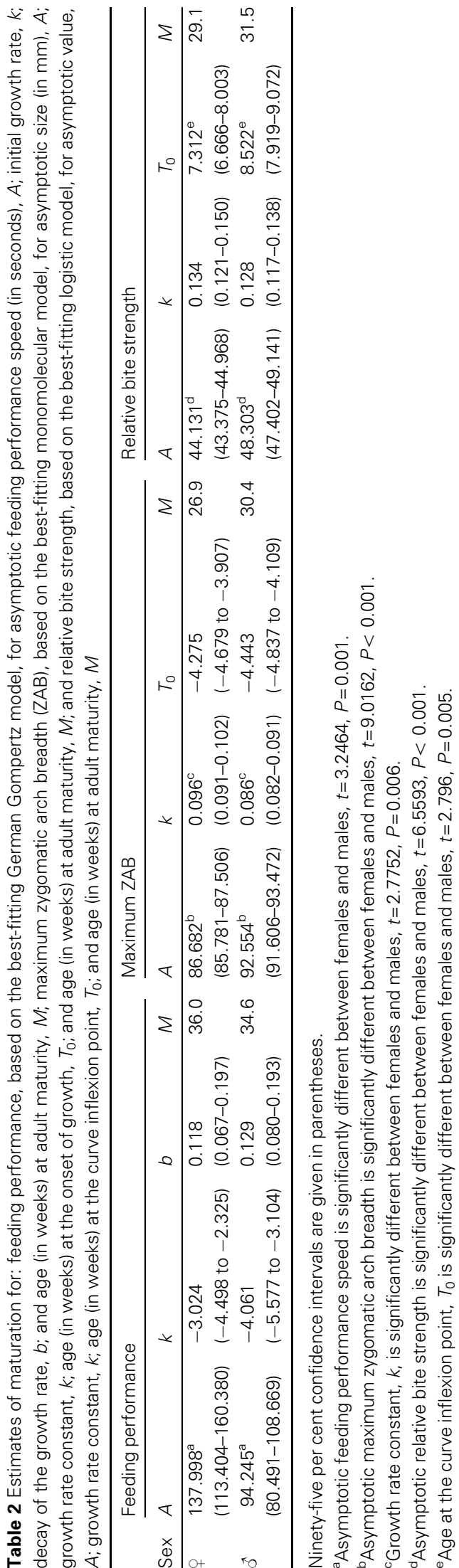

significantly larger for males $(P<0.001)$, but growth rate was significantly faster for females $(P=0.006)$ (Table 2$)$. The model that best fit relative bite strength, the logistic model (Table 1, supporting information Table S4), estimated maturation for relative bite strength at 29.1 weeks for females and 31.5 weeks for males; asymptotic relative bite strength was significantly greater for males than females $(P<0.001)$. Females were significantly younger than males at the growth curve inflexion point, by which they had reached $50 \%$ of their adult relative bite strength $(P=0.005)$ (Table 2).

\section{Maturation and life history}

Feeding performance and biomechanics reach maturity long after weaning at 6 weeks of age (Table 3); further, during the course of ontogeny, feeding performance maturation lags considerably behind biomechanical maturation (Fig. 8a), as well as skull size and shape maturation (Fig. $8 \mathrm{~b}$ and c). At weaning, feeding performance for males is extremely immature at only $16 \%$ of adult values; likewise, for females, it is only $23 \%$ of the adult values (Table 4 ). Six weeks later, at the onset of tooth replacement, feeding performance among females has improved to $42 \%$ of the adult values, while males show an even greater improvement to $47 \%$ of the adult values. By the time adult dentition is complete at 26 weeks, feeding performance for both sexes has improved to $c .86 \%$ of adult values but does not reach full maturity for another 8-10 weeks (Fig. 8a, Table 3). Because data for the mechanical advantage of the temporalis did not fit a traditional growth curve, we were unable to model predictions of maturity. Instead, we calculated the relative maturity of mechanical advantage of the temporalis for the younger cloud of data by dividing its mean value by that of the older (adult) cloud of data. Mean value of mechanical advantage of the temporalis for younger females was 0.376 , and for older females it was 0.508 ; males had greater mechanical advantage at both ages than did females, 0.383 among the

Table 3 Age at maturation (95\% of adult value), as estimated from best-fit models; feeding performance and biomechanics (this study) and skull size and shape (La Croix et al., 2011)

\begin{tabular}{llll}
\hline & \multicolumn{2}{l}{$\begin{array}{l}\text { Age at maturation } \\
\text { (weeks) }\end{array}$} & \\
\cline { 2 - 3 } & Female & Male & Best-fit model \\
\hline $\begin{array}{l}\text { Feeding performance } \\
\text { Biomechanics }\end{array}$ & 36.0 & 34.6 & German Gompertz \\
$\quad$ Maximum ZAB & 26.9 & 30.4 & Monomolecular \\
$\quad \begin{array}{l}\text { Relative bite strength } \\
\text { Skull size }\end{array}$ & 29.1 & 31.5 & Logistic \\
$\quad$ Ventral cranium & 22.0 & 22.5 & Logistic \\
$\quad$ Lateral cranium & 21.8 & 22.5 & Logistic \\
$\quad \begin{array}{l}\text { Lateral mandible } \\
\text { Skull shape }\end{array}$ & 21.7 & 23.0 & Logistic \\
$\quad$ Ventral cranium & 18.1 & 17.2 & Logistic \\
$\quad$ Lateral cranium & 20.7 & 20.9 & Logistic \\
$\quad$ Lateral mandible & 28.2 & 28.2 & Logistic \\
\hline
\end{tabular}



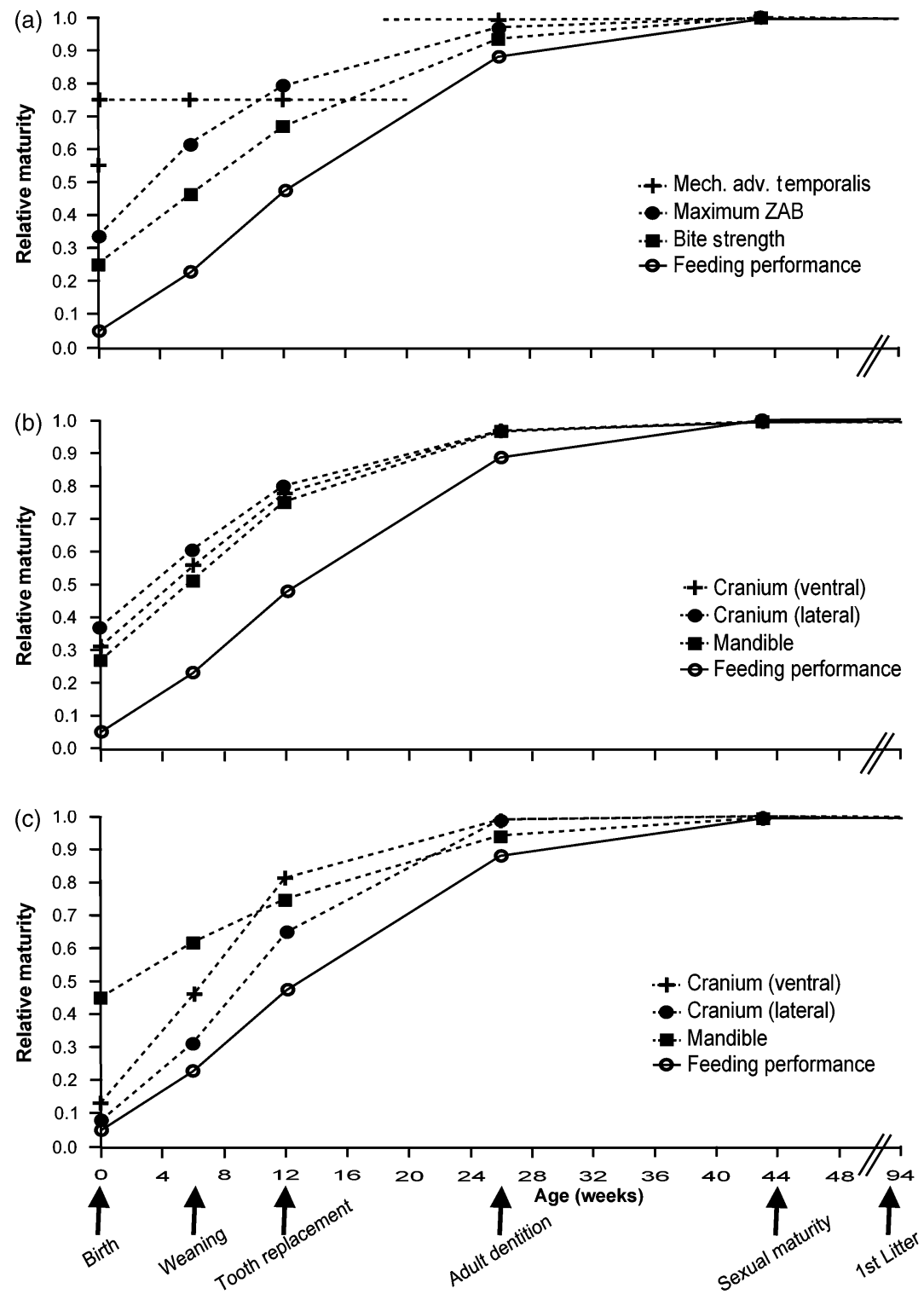

Figure 8 Timeline illustrating the relative maturity of coyote feeding performance to that of feeding biomechanics (a), skull size (b) and skull shape (c) in relation to major life-history events. Relative maturity for biomechanics (this study) and skull morphology (La Croix et al., 2011) is indicated with a dashed line, and for feeding performance (this study) with a solid line. Maturation of mechanical advantage of the temporalis (a) does not follow a traditional growth pattern, but is, instead maintained within two discrete ranges throughout ontogeny, one for younger animals and one for older animals (see supporting information Fig. S2); here, we have diagrammed the relative maturity of the younger group as calculated by dividing the mean younger group mechanical advantage by that of the older (adult) group (see Table 5). younger males, and 0.516 among the older males (Table 5). Relative maturity of mechanical advantage of the temporalis for young animals of both sexes is extremely mature at $74 \%$ of the adult value, especially in contrast to other biomechanical estimates (Fig. 8a). Maturation of mechanical advantage occurs after deciduous tooth replacement but before eruption of adult dentition is complete (Fig. 8a). Maximum ZAB for both sexes is only one-third of adult size at birth, but doubles by the age of weaning 6 weeks later (Table 4). By the onset of deciduous tooth replacement, rapid early growth in maximum ZAB is apparent, as females are already at $79 \%$ of the adult values and males are at $76 \%$ of the adult values (Fig. 8a). Subsequently growth slows, with female coyotes reaching adult maximum ZAB 1 week after adult dentition is completely erupted; males mature 3 weeks after females (Table 3 ). The maturation of relative bite strength among males lags slightly behind females throughout development, and reaches adult values after females have matured. At birth, relative bite strength among males and females is c. $26 \%$ of adult values, which is less mature than maximum $\mathrm{ZAB}$, but more mature than feeding performance (Table 4, Fig. 8a). By the age of weaning, relative bite strength has improved to $46 \%$ of adult values for females and $42 \%$ of adult values for males. At the onset of deciduous tooth replacement, females continue to show greater maturity, at $65 \%$ of adult values, than do males, which are at $61 \%$ of adult values. With the completion of adult tooth eruption at 26 weeks, relative bite strength remains more mature for females, at $93 \%$ of adult values, than for males, which are at $90 \%$ of adult values. Females attain relative bite strength maturity 3 weeks after adult dentition is complete and 2 weeks before males reach 
Table 4 Relative maturity of feeding performance, maximum zygomatic arch breadth (ZAB) and relative bite strength, based on parameters of its best-fit model

\begin{tabular}{|c|c|c|c|c|c|c|}
\hline \multirow[b]{2}{*}{ Age (weeks) } & \multicolumn{2}{|c|}{ Feeding performance } & \multicolumn{2}{|c|}{ Maximum ZAB } & \multicolumn{2}{|c|}{ Relative bite strength } \\
\hline & Female & Male & Female & Male & Female & Male \\
\hline 0 & 0.058 & 0.020 & 0.338 & 0.318 & 0.272 & 0.251 \\
\hline 4 & 0.162 & 0.093 & 0.549 & 0.518 & 0.391 & 0.359 \\
\hline 6 & 0.233 & 0.158 & 0.628 & 0.594 & 0.456 & 0.420 \\
\hline 8 & 0.311 & 0.238 & 0.693 & 0.659 & 0.524 & 0.483 \\
\hline 12 & 0.473 & 0.418 & 0.791 & 0.758 & 0.653 & 0.609 \\
\hline 16 & 0.619 & 0.590 & 0.858 & 0.829 & 0.764 & 0.722 \\
\hline 20 & 0.736 & 0.726 & 0.903 & 0.879 & 0.847 & 0.812 \\
\hline 24 & 0.822 & 0.824 & 0.934 & 0.914 & 0.905 & 0.878 \\
\hline 26 & 0.854 & 0.860 & 0.946 & 0.928 & 0.926 & 0.903 \\
\hline 28 & 0.882 & 0.889 & 0.955 & 0.939 & 0.942 & 0.923 \\
\hline 32 & 0.923 & 0.931 & 0.970 & 0.957 & 0.965 & 0.953 \\
\hline 36 & 0.950 & 0.958 & 0.980 & 0.970 & 0.980 & 0.971 \\
\hline
\end{tabular}

Relative maturity is calculated by dividing a model's predicted value at a given age by the corresponding asymptotic value.

Table 5 Mean values of mechanical advantage of the temporalis, for two age groups of coyotes and relative maturity of the younger group (indicated in bold), as calculated by dividing mean younger group mechanical advantage by that of the older (adult) group

\begin{tabular}{lclll}
\hline \multicolumn{4}{l}{ Mechanical advantage of the temporalis } & \\
\hline & Age (weeks) & Female & Male & All \\
\hline Younger & $0.1-14.3$ & 0.376 & 0.383 & 0.380 \\
Older & $21.1-516.3$ & 0.508 & 0.516 & 0.512 \\
Relative maturity of younger group & $\mathbf{0 . 7 4 2}$ & $\mathbf{0 . 7 4 3}$ & $\mathbf{0 . 7 4 3}$ \\
\hline
\end{tabular}

maturity (Table 3). Female coyotes attain their adult maximum ZAB and relative bite strength earlier than males, but they are disadvantaged in comparison to males with smaller maximum ZABs and lower relative bite strength; female feeding performance not only matures later than males, but it is also significantly less than that of males (Table 2).

\section{Discussion}

Our results demonstrate that juvenile coyotes are handicapped by an immature food processing apparatus, relatively poor biomechanical abilities and slower food processing times compared with adults. For newly weaned 6-week-olds, such handicaps might be insurmountable. While initial parental provisioning provides pups with access to adult food items, pups must still be capable of processing those foods. That coyote feeding performance and biomechanics do not mature until long after weaning may, in part, explain why juvenile coyotes capitalize on that portion of the adult diet that is most easily obtained or subdued (Clark, 1972; Bowen, 1978; Johnson, 1978; Andelt et al., 1987; Gese, Ruff \& Crabtree, 1996; Hidalgo-Mihart et al., 2001; Arjo et al., 2002; Hernandez et al., 2002). Juvenile coyotes ingest mostly small mammals, vegetation, invertebrates and birds whereas adults consume larger mammals, fewer invertebrates and few birds (Hawthorne, 1970).
Our results also show that the development of feeding performance is asynchronous with development of both feeding biomechanics and skull morphology (La Croix et al., 2011) (Fig. 8a-c). Feeding performance, feeding biomechanics and skull morphology exhibit different temporal patterns of development, especially relative to early life-history milestones. Skull size, mandibular shape and feeding biomechanics are dramatically more mature across ontogeny than is feeding performance, and these features achieve adult values much earlier in life. In particular, the relative maturity of mandibular shape during the youngest age intervals contributes to the interesting pattern of mature and constant mechanical advantage during early ontogeny; despite the early maturation of these features, feeding performance nevertheless lags behind. Cranial shape, the only measure aside from feeding performance that is extremely immature at birth, matures much more quickly than does feeding performance over the course of ontogeny. Indeed, feeding performance lags behind the relative maturity of all other measures considered here, and matures much later than most (Fig. 9a).

The developmental asynchrony shown here between feeding performance and morphological variables suggests that a certain minimum threshold of physical growth and development, together with the associated development of biomechanics, are required to produce effective mastication. In addition, feeding biomechanics exhibits interesting developmental patterns during ontogeny, suggesting adaptations in young animals to balance conflicting demands of their immediate need to process food with growth of the feeding apparatus toward an adult form. There is also evidence that males and females resolve these conflicts differently, as females trade earlier maturity for smaller maximum ZAB, decreased relative bite strength, and diminished feeding performance, compared with males.

At weaning, coyote pups are unable to do more than nibble at the edges of a test biscuit. However, feeding performance quickly shows dramatic improvement and 12week-old pups can process a $32 \mathrm{~g}$ biscuit; their feeding 


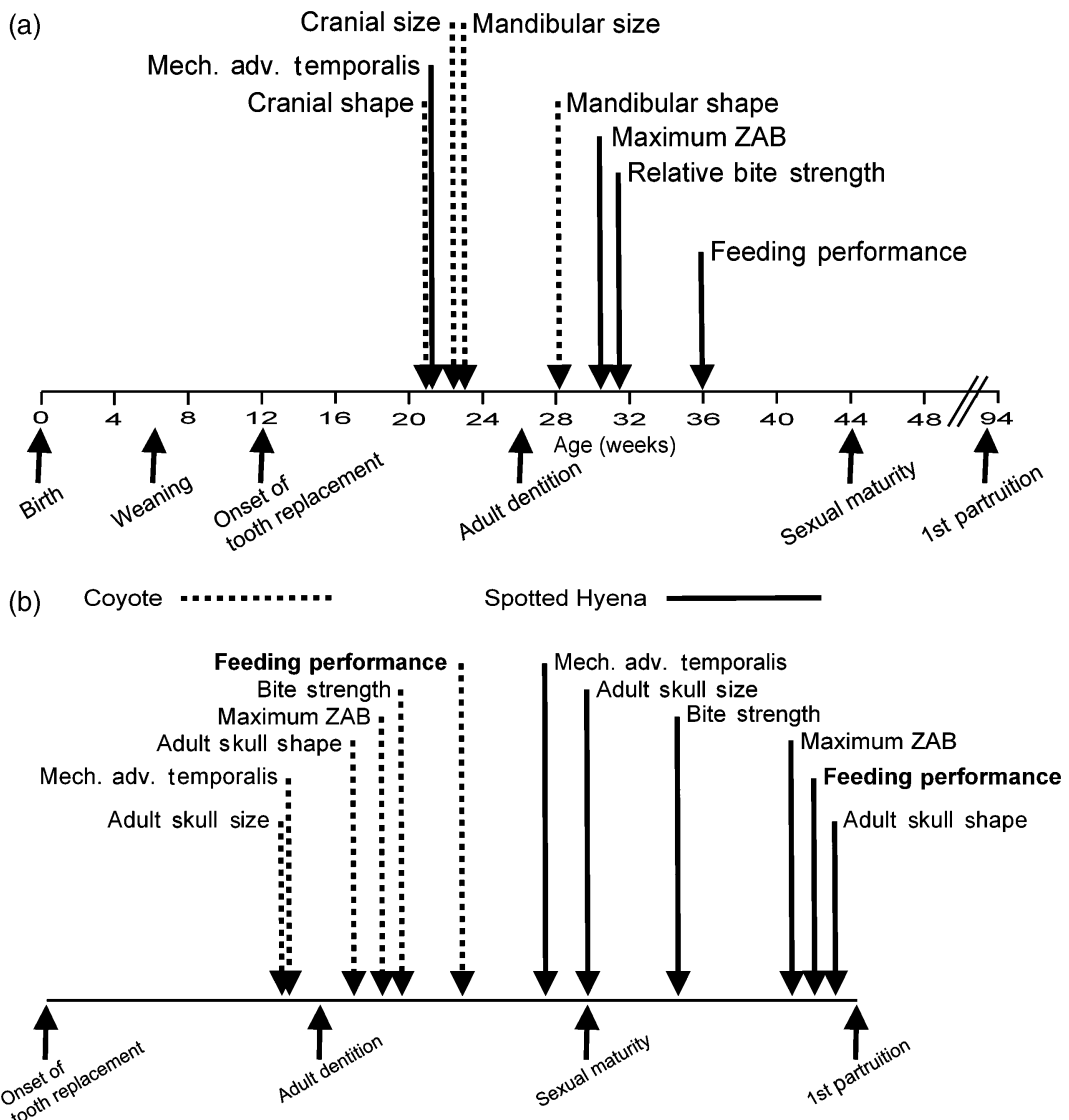

Figure 9 Timelines illustrating: (a) the age at maturation for coyote feeding performance, biomechanics and skull morphology in relation to major life-history events. Maturation for skull morphology (La Croix et al., 2011) is indicated with a dashed line, and for feeding performance and biomechanics (this study) with a solid line. Where maturation age differed between sexes for a measure, the latest maturation age is diagrammed. (b) Comparison of maturation timing of feeding performance and biomechanics for coyotes and spotted hyenas in relation to major life-history events. Maturation for coyotes (this study and La Croix et al., 2011) is indicated with a dashed line, and for spotted hyenas (Tanner et. al., 2010 and J. B. Tanner, unpubl. data) with a solid line. The latest maturation age is diagrammed for all measures. performance has already improved to nearly half of adult values (Fig. 8a). However, by 12 weeks of age the biomechanics that contribute to mastication are already nearly $80 \%$ mature, so feeding performance remains relatively immature in comparison to feeding biomechanics. Despite rapid early improvement in feeding performance, its maturation occurs late, relative to the maturation of feeding biomechanics, and especially late relative to achievement of maturity in skull size and shape (Fig. 9a).

During early ontogeny, the relative maturity of feeding biomechanics might lead one to expect more mature feeding performance, especially because mechanical advantage of the temporalis is maintained at c. $74 \%$ of adult values during the first 14 weeks of life (Fig. 8a). Remarkably, early mechanical advantage is accomplished by an elegant maintenance of in- and out-lever arm length proportions over a developmental period wherein dramatic changes in cranial and mandibular size and shape occur (La Croix et al., 2011), including tooth eruption and replacement. Isometric growth might be expected to maintain these lever arm length proportions, but we found that this was not the case (supporting information Fig. S3). Initially, growth in the length of the out-lever arm is greater than that of the in-lever arm; at 12 weeks, the distance between the deciduous bite point and the mandibular condyle is already equivalent to the length of the adult out-lever arm. Subsequently, and in conjunction with ongoing tooth row elongation, the adult mandibular carnassial erupts slightly behind the deciduous carnassial and replaces it; the distance between the mandibular condyle and the adult bite point is conserved as the outlever arm stops growing. In contrast, the in-lever arm length continues to increase, resulting in a shift in the mechanical advantage of the temporalis from the range of young animals to that of adults. By 21 weeks, growth of the inlever arm length also ceases, resulting in maturation of the mechanical advantage of the temporalis. This early maturation age for mechanical advantage makes it temporally disjunct from the maturation of feeding performance, thus younger animals are beneficiaries of a unique punctuated growth pattern during the period when they are constrained by immature chewing muscles and tooth replacement. In the absence of this maturation pattern, feeding performance would undoubtedly fare worse, particularly during the challenging period immediately after weaning, when young animals must first feed themselves.

Conflicting demands between the immediate need to process food and the growth of the feeding apparatus toward an adult form were resolved differently by females and males. During ontogeny, growth of the maximum ZAB is significantly faster for females than for males, affording them early advantage as they achieve their adult maximum $\mathrm{ZAB}$ and adult relative bite strength sooner than males. The males however, continue to grow, albeit more slowly and achieve larger maximum $\mathrm{ZABs}$ and larger relative bite 
strengths. This pays off for males with faster feeding performances that mature earlier than those of females who are slower at processing food, and who achieve adult foodprocessing levels later.

Maturation of maximum ZAB, relative bite strength and mandibular shape is more temporally coincident with maturation of feeding performance than is skull size, skull shape or mechanical advantage of the temporalis (La Croix et al., 2011) (Fig. 9a). Because mechanical advantage of the temporalis matures so early ( 21 weeks), it is the subsequent and ongoing growth in maximum $\mathrm{ZAB}$, reflecting augmentation of the temporalis muscles after 21 weeks of age that drives the development of relative bite strength and ultimately, that of feeding performance. The maturation of maximum $\mathrm{ZAB}$ by 30 weeks appears to set the foundation for the maturation of relative bite strength by 32 weeks and maturation of feeding performance by 36 weeks. It should be noted that maximum $\mathrm{ZAB}$, used here as a proxy for muscle strength in the calculation of relative bite strength, probably underestimates mass and cross-sectional area of the primary mastication muscles, because it does not take into account the substantial relative narrowing of the basicranium during coyote growth and development; this change in skull shape yields a larger space within the zygomatic arch for temporalis muscle deposition after skull shape reaches maturity (La Croix et al., 2011).

It is not presently known whether the asynchrony shown here among the development of feeding performance, feeding biomechanics and skull morphology in the coyote represents a more generalized mammalian pattern. In fact, only one other study, on the spotted hyena Crocuta crocuta (Tanner et al., 2010), has concurrently examined ontogenetic patterns of feeding performance, biomechanics and skull shape change in relation to life-history milestones. Hyenas, unlike coyotes, are capable of cracking open large bones as adults, using craniodental adaptations for durophagy that include a vaulted forehead, a large sagittal crest, massive zygomatic arches and robust premolars with crackresistant enamel. Another distinction between hyenas and coyotes may similarly be related to morphological demands of durophagy; that is, the hyena's life history is notable for its protracted period of maternal dependence relative to those in other large carnivores (Watts et al., 2009). Previous research has shown that skull ontogeny in the spotted hyena, like that of coyotes, demonstrates relative synchrony in cranial and mandibular growth but asynchrony in cranial and mandibular shape development, cranial size and shape maturation, and mandibular size and shape maturation (Tanner et al., 2010; La Croix et al., 2011). The most striking differences between coyotes and hyenas, however, are the sequence of maturation events and their timing relative to key life-history milestones (Fig. 9b). Feeding performance in coyotes matures after the maturation of skull size and shape and is the last measure to mature. By contrast, in the spotted hyena, feeding performance maturation is dramatically delayed, occurring long after skull size maturation, but slightly before full maturation of skull shape (Watts et al., 2009). Patterns of maturation in regard to feeding biome- chanics also differ between coyotes and hyenas. Whereas maturation of mechanical advantage of the temporalis coincides with maturation of skull size in both species, maximum $\mathrm{ZAB}$ matures before relative bite strength in coyotes, but this pattern is reversed in hyenas. Further, whereas maturation of maximum $\mathrm{ZAB}$ and relative bite strength are temporally coincident in coyotes, they are temporally disjunct in hyenas. Although use of maximum $\mathrm{ZAB}$ as a proxy for muscle strength may underestimate relative bite strength in coyotes, this problem would only be exacerbated in a hypercarnivore like the spotted hyena with its massive temporalis muscles.

Feeding performance in both coyotes and spotted hyenas matures long after weaning, suggesting that young individuals experience significant handicaps during feeding between weaning and the age at which performance maxima are achieved. However, whereas all aspects of maturation in behavioral and morphological traits associated with feeding have reached full maturity by the age of sexual maturity in coyotes, this is not the case in spotted hyenas. Indeed, various morphological aspects of the feeding apparatus, such as maximum ZAB and adult skull shape, do not reach full maturity until long after puberty in spotted hyenas, and feeding performance maxima are not achieved until the mean age of first parturition. Delayed feeding performance, biomechanics and skull maturation during ontogeny of spotted hyenas may be explained as trade-offs associated with the ability to crack open large bones in adulthood. The dominant feature of post-weaning shape change in the spotted hyena skull is the development of the bony areas of muscle insertion: zygomatic arches expand and the sagittal and nuchal crests develop (Tanner et al., 2010). It has previously been shown for coyotes, which lack such specialized adult function as bone cracking, that there is a more modest delay in skull maturation than that seen in spotted hyenas (La Croix et al., 2011). Here, we have shown that a substantial delay in maturation also exists for the achievement of feeding performance and feeding biomechanics, but this delay is shorter in the less-specialized species.

The temporal coincidence of weaning and adult tooth eruption may imply that juveniles are capable of effectively competing for food with conspecifics at this time (Biknevicius \& Van Valkenburgh, 1996). However, neither the results presented here nor the data from hyenas (Binder, 1998; Binder \& Van Valkenburgh, 2000; Tanner, 2007) support that hypothesis. Instead, our data suggest that juvenile coyotes are handicapped in their feeding performance, biomechanics, and skull morphology for up to 7 months. Even though biparental provisioning may occur after weaning in coyotes, as it does in other canids, provisioning stops long before juveniles reach their adult performance capabilities. Thus, young animals must feed themselves after weaning and adult tooth eruption despite being considerably disadvantaged relative to the adults with which they must compete for food. Such handicaps are apparent in the generalist coyote as well as in the highly specialized bone-cracking hyenas.

Factors other than biomechanical constraints, as seen in coyotes, or selective pressures associated with adult dietary 
demands, as seen in hyenas, may influence the maturation of feeding performance in these and other carnivores, and thus determine how long young animals remain handicapped during feeding competition. First, feeding performance requires a functional relationship between the parts of the skull; for example, the cranium and the mandible must work in concert with each other to form an effective feeding apparatus. This feeding apparatus must remain functional across ontogeny, while shape and size of both cranium and mandible are changing. Asynchronous development of cranium and mandible might delay maturation of feeding performance. Second, efficient food processing takes practice; the effects of learning were not considered here. Third, tooth development and strength may limit biting ability.

By looking at the ontogeny of feeding performance and biomechanics concurrently, examining their maturation patterns, and placing both within the context of life history, we can shed light on the processes at work during the protracted period of morphological and behavioral development of carnivores. Additional studies on carnivores are needed to provide a richer context for interpreting the relationships between life histories and the maturation of morphology and behavior, and life history. We have demonstrated here, that, while mandibular growth patterns are important to early mechanical advantage of the temporalis, it is the ongoing development of the primary mastication muscles, the temporalis that can have an acute effects on the maturation of bite strength and ultimately feeding performance and fitness.

\section{Acknowledgments}

We are grateful to Doris Zemlicka, Jeff Schultz, Stacey Brummer, Patrick Darrow and the entire staff at the NWRC Logan Field Station for their work in collecting the specimens used here, their assistance in rearing pups, and for their cooperation and support. We are also indebted to Don Swiderski, Laura Abraczinskas, Paula Hildebrandt, Gwen Webster and Katherine Leonard for their help on this project. This work was funded by grants-in-aid from the Graduate School, the College of Natural Sciences and the Department of Zoology at Michigan State University to S.L.C. Portions of this work were also funded by NSF grants I0B0618022 and I0S0819437.

\section{References}

Andelt, W.F., Kie, J.G., Knowlton, F.F. \& Cardwell, K. (1987). Variation in coyote diets associated with season and successional changes in vegetation. J. Wildl. Mgmt. 51, 273-277.

Arjo, W.M., Pletscher, D.H. \& Ream, R.R. (2002). Dietary overlap between wolves and coyotes in northwestern Montana. J. Mammal. 83, 754-766.

Bekoff, M. (1977). Canis latrans. Mamm. Species 79, 1-9.

Bekoff, M. (2001). Behavioral development in coyotes and eastern coyotes. In Coyotes: biology, behavior, and man- agement: 97-126. Bekoff, M. (Ed.). Caldwell: The Blackburn Press.

Bekoff, M. \& Gese, E.M. (2003). Coyote (Canis latrans). In Wild mammals of North America: biology, management, and conservation: 467-481. Feldhamer, G.A., Thompson, B.C. \& Chapman, J.A. (Eds). Baltimore: John Hopkins University Press.

Bekoff, M. \& Jamieson, R. (1975). Physical development in coyotes (Canis latrans), with a comparison to other canids. J. Mammal. 56, 685-692.

Biknevicius, A.R. \& Van Valkenburgh, B. (1996). Design for killing: craniodental adaptations of predators. In Carnivore behavior, ecology and evolution: 393-428. Gittleman, J.L. (Ed.). Ithaca: Cornell University Press.

Binder, W.J. (1998). Functional aspects of tooth and jaw development in large carnivores. $\mathrm{PhD}$ dissertation, University of California, Los Angeles.

Binder, W.J. \& Van Valkenburgh, B. (2000). Development of bite strength and feeding behaviour in juvenile spotted hyenas (Crocuta crocuta). J. Zool. (Lond.) 252, 273-283.

Bowen, W.D. (1978). Social organization of the coyote in relation to prey size. $\mathrm{PhD}$ dissertation, University of British Columbia, Vancouver.

Christiansen, P. \& Adolfsen, J. (2005). Bite forces, canine strength and skull allometry in carnivores (Mammalia, Carnivora). J. Zool. (Lond.) 266, 133-151.

Clark, F.W. (1972). Influence of jackrabbit density on coyote population change. J. Wildl. Mgmt. 36, 343-356.

Ellis, J.L., Thomason, J.J., Kebreab, E. \& France, J. (2008). Calibration of estimated biting forces in domestic canids: comparison of post-mortem and in vivo measurements. J. Anat. 212, 769-780.

Erickson, G.M., Lappin, A.K. \& Vliet, K.A. (2003). The ontogeny of bite-force performance in American alligator (Alligator mississippiensis). J. Zool. (Lond.) 260, 317-327.

Fiorello, C.V. \& German, R.Z. (1997). Heterochrony within species: craniofacial growth in giant, standard and dwarf rabbits. Evolution 51, 250-261.

Gaillard, J.-M., Pontier, D., Allaine, D., Loison, A., Herve, J.-C. \& Heizmann, A. (1997). Variation in growth form and precocity at birth in eutherian mammals. Proc. Roy. Soc. Lond. Ser. B 264, 859-868.

Gese, E.M., Ruff, R.L. \& Crabtree, R.L. (1996). Intrinsic and extrinsic factors influencing coyote predation of small animals in Yellowstone National Park. Can. J. Zool. 74, 784-797.

Gittleman, J.L. \& Van Valkenburgh, B. (1997). Sexual dimorphism in the canines and skulls of carnivores: effects of size, phylogeny, and behavioural ecology. J. Zool. (Lond.) 242, 97-117.

Greaves, W.S. (1983). A functional-analysis of carnassial biting. Biol. J. Linn. Soc. 20, 353-363.

Greaves, W.S. (1985). The mammalian postorbital bar as a torsion-resisting helical strut. J. Zool. (Lond.) 207, 125-136. 
Hawthorne, V.M. (1970) Movements and food habits of coyotes in the Sagehen Creek Basin and Vicinity. MSc thesis, University of Nevada, Reno.

Hernandez, L., Parmenter, R.R., Dewitt, J.W., Lightfoot, D.C. \& Laundre, J.W. (2002). Coyote diets in the Chihuahuan Desert, more evidence for optimal foraging. J. Arid Environ. 51, 613-624.

Herrel, A. \& Gibb, A.C. (2006). Ontogeny of performance in vertebrates. Physiol. Biochem. Zool. 79, 1-6.

Hidalgo-Mihart, M.G., Cantu-Salazar, L., Lopez-Gonzalez, C.A., Martinez-Meyer, E. \& Gonzalez-Romero, A. (2001). Coyote (Canis latrans) food habits in a tropical deciduous forest of western Mexico. Am. Midl. Nat. 146, 210-216.

Hiiemae, K.M. \& Crompton, A.W. (1985). Mastication, food transport, and swallowing. In Functional vertebrate morphology: 262-290. Milton Hildebrand, D.M.B., Liem, K.F. \& Wake, D.B. (Eds). Cambridge: Harvard University Press.

Hildebrand, M. (1984). Analysis of vertebrate structure. New York: Wiley.

Hurov, J., Henry-Ward, W., Phillips, L. \& German, R. (1988) Growth allometry of craniomandibular muscles, tendons, and bones in the laboratory rat (Rattus norvegicus): relationships to oromotor maturation and biomechanics of feeding. Am. J. Anat. 182, 381-394.

Johnson, M.K. (1978). Food habits of coyotes in southcentral Idaho. PhD dissertation, Colorado State University, Fort Collins.

Koehl, M. (1996). When does morphology matter? Annu. Rev. Ecol. Syst. 27, 501-542.

La Croix, S., Holekamp, K.E., Shivik, J.A., Lundrigan, B.L. \& Zelditch, M.L. (2011). Ontogenetic relationships between cranium and mandible in coyotes and hyenas. J. Morphol. 272, 662-674.

Langenbach, G.E.J. (2001). Mammalian feeding motor patterns. Am. Zool. 41, 1338-1351.

Monteiro, L.R., Lessa, L.G. \& Abe, A.S. (1999). Ontogenetic variation in skull shape of Thrichomys apereoides (Rodentia: Echimyidae). J. Mammal. 80, 102-111.

Radinsky, L.B. (1981). Evolution of skull shape in carnivores 1. Representative modern carnivores. Biol. J. Linn. Soc. 15, 369-388.

Schumacher, G.H. (1985). Comparative functional-anatomy of jaw muscles in reptiles and mammals. Fortsch. Der Zool. 30, 203-212.

Sheets, D.H. (2003). IMP - integrated morphometrics package. Buffalo: Department of Physics, Canisius College.

Simpson, C.D. (1978). Comparative mammalian mastication. Angle Orthodont. 48, 93-105.

Smith, K.K. (1993). The form of the feeding apparatus in terrestrial vertebrates: studies of adaptation and constraint. In The skull: 150-185. Hanken, J. \& Hall, B.K. (Eds). Chicago: University of Chicago Press.

Tanner, J.B. (2007). Behavioral and morphological development in a female-dominated species, the spotted hyena (Crocuta croctuta). PhD dissertation. Michigan State University, East Lansing.
Tanner, J.B., Zelditch, M.L., Lundrigan, B.L. \& Holekamp, K.E. (2010). Ontogenetic change in skull morphology and mechanical advantage in the spotted hyena (Crocuta crocuta). J. Morphol. 271, 353-365.

Thomason, J.J. (1991). Cranial strength in relation to estimated biting forces in some mammals. Can. J. Zool. - Rev. Can. Zool. 69, 2326-2333.

Thompson, E.N., Biknevicius, A.R. \& German, R.Z. (2003). Ontogeny of feeding function in the gray short-tailed opossum Monodelphis domestica: empirical support for the constrained model of jaw biomechanics. J. Exp. Biol. 206, 923-932.

Turnbull, W.D. (1970). Mammalian masticatory apparatus. Fieldiana Geol. 18, 147-356.

Van Valkenburgh, B. (1989). Carnivore dental adaptations and diet: a study of trophic diversity within guilds. In Carnivore behavior, ecology, and evolution: 410-436. Gittleman, J.L. (Ed.). Ithaca: Cornell University Press.

Wainwright, P.C. \& Reilly, S.M. (1994). Ecological morphology. Chicago: University of Chicago Press.

Watts, H.E., Tanner, J.B., Lundrigan, B.L. \& Holekamp, K.E. (2009). Post-weaning maternal effects and the evolution of female dominance in the spotted hyena. Proc. Roy. Soc. Lond. Ser. B 276, 2291-2298.

Weijs, W.A. (1994). Evolutionary approach of masticatory motor patterns in mammals. Adv. Comp. Environ. Physiol. 18, 281-320.

Zelditch, M.L., Lundrigan, B.L., Sheets, H.D. \& Garland, J.T. (2003). Do precocial mammals develop at a faster rate? A comparison of rates of skull development in Sigmodon fulviventer and Mus musculus domesticus. J. Evol. Biol. 16, 708-720.

\section{Supporting Information}

Additional Supporting Information may be found in the online version of this article:

Figure S1. Schedule of tooth eruption and replacement (including post-canine teeth) in coyotes. The presence of each deciduous (D) or Adult (A) tooth is indicated for the cranium (a) and mandible (b). All coyote skull specimens examined at each age displayed the specified tooth configuration.

Figure S2. Comparison of mean mechanical advantage of the temporalis between coyotes with primarily deciduous dentition and those with primarily adult dentition.

Figure S3. Plots of the regression of the out-lever arm length (distance between the mandibular condyle and the bite point) on the in-lever arm length (distance between the mandibular condyle and the dorsal tip of the coronoid process) (a) and the residuals (b).

Table S1. Canis latrans specimens

Table S2. Canis latrans feeding performance subjects.

Table S3. Canis latrans bite strength subjects. 
Table S4. Relative fit of the eight growth models fitted to the feeding performance, maximum zygomatic arch breadth and relative bite strength. The AIC weight evaluates relative goodness-of-fit by balancing the distance between model and data by degrees of freedom. AC refers to serial autocorrelation among residuals of the model (statistically significant are indicated by an asterisk). The AIC is not applied to models with significant AC. The model judged best is in bold type.
As a service to our authors and readers, this journal provides supporting information supplied by the authors. Such materials are peer-reviewed and may be re-organized for online delivery, but are not copy-edited or typeset. Technical support issues arising from supporting information (other than missing files) should be addressed to the authors. 